\title{
Helicobacter pylori eradication therapy for the remnant stomach after gastrectomy
}

\author{
Norio Matsukura ${ }^{1}$, Takashi Tajiri ${ }^{1}$, Shunji Kato ${ }^{1}$, Akiyoshi Togashi ${ }^{1}$, Gotaro Masuda ${ }^{1}$, Itsuo Fujita ${ }^{1}$, \\ Akira Tokunaga ${ }^{1}$, and Nobutaka Yamada ${ }^{2}$ \\ ${ }^{1}$ Surgery for Organ Function and Biological Regulation (First Department of Surgery), Nippon Medical School, 1-1-5 Sendagi, Bunkyo-ku, \\ Tokyo 113-8603, Japan \\ ${ }^{2}$ Second Department of Pathology, Nippon Medical School, Tokyo, Japan
}

\begin{abstract}
Background. The remnant stomach after surgery for gastric cancer is at high risk for the metachronous development of multiple gastric cancers. Here, we report on eradication therapy of Helicobacter pylori in the remnant stomach, comparing the eradication rate with that in unoperated stomachs. We examined gross and histological changes after treatment. Methods. Forty $\mathrm{H}$. pylori-positive patients after distal gastrectomy were treated with proton pump inhibitor (PPI)-based dual and triple therapies. After eradication, histological changes were classified on the basis of the updated Sydney system.

Results. The eradication rate in the remnant stomach was $70 \%$ (14 of 20) after dual therapy and 90\% (18 of 20) after triple therapy, using per-protocol analysis, and these rates were comparable to the rates of $70 \%$ (186 of 264$)$ and $88 \%(58$ of 66), respectively, in nonsurgery patients. After eradication, three sites in the remnant stomach showed similar histological changes: significant decreases in inflammation and activity scores $(P<0.001)$ and no significant changes in glandular atrophy and intestinal metaplasia scores.

Conclusion. PPI-based therapy was as effective for $\boldsymbol{H}$. pylori eradication in the remnant stomach as in the unoperated stomach, and eradication therapy resulted in a significant decrease in inflammatory cell infiltration of the mucosal layer.
\end{abstract}

Key words Helicobacter pylori $\cdot$ Remnant stomach $\cdot$ Eradication $\cdot$ Triple therapy $\cdot$ Sydney system

\section{Introduction}

Stump cancer after peptic ulcer surgery has been investigated, and bile (alkaline) reflux has been found to be a main causative factor of such new cancers $[1,2]$. By contrast, cancer in the remnant stomach after surgery for

Offprint requests to: N. Matsukura

Received: January 21, 2003 / Accepted: February 26, 2003 early gastric cancer is metachronous multiple cancer, and $H$. pylori infection may be a causative factor [3]. Much human and animal evidence has shown a close association between $H$. pylori infection and gastric cancer [4-6]. Although cancer development is a multifactorial process [7], H. pylori infection increases the risk of gastric cancer. "The Maastricht Consensus Report" strongly recommends $H$. pylori eradication therapy following early resection for gastric cancer [8]. There are some data showing that $H$. pylori eradication is associated with a decrease in the recurrence rate in patients with early gastric cancer that is resected endoscopically $[9,10]$. However, few reports have been published on H. pylori eradication therapy in the remnant stomach $[11,12]$. In this study, we investigated the following factors in the remnant stomach after distal gastrectomy: (1) the eradication rate of $H$. pylori in comparison with that in the unoperated stomach, (2) changes in chronic gastritis scores, according to the updated Sydney system [13], after H. pylori eradication therapy, in comparison with scores in the unoperated stomach, and (3) changes in gross endoscopic findings after H. pylori eradication.

\section{Patients and methods}

\section{Patients}

The remnant stomachs in 137 patients after distal gastrectomy were $H$. pylori-positive, and 64 were $H$. pylorinegative; 40 of the $H$. pylori-positive patients were randomly selected for $H$. pylori eradication therapy (Table 1). All 40 patients were tested for H. pylori 4-6 weeks after the start of the eradication therapy; 14 of them were followed endoscopically for more than 1 year (average, 21 months) and histological examinations were performed. Among the untreated patients, 22 (15 $\mathrm{H}$. pylori-positive and $7 \mathrm{H}$. pylori-negative) were endoscopically followed for more than 1 year (average, 32 
Table 1. Characteristics of patients with Helicobacter pylori infection and eradication therapy for the gastric remnant

\begin{tabular}{|c|c|c|c|c|c|}
\hline & $n$ & $\begin{array}{l}\text { H. pylori- } \\
\text { positive }\end{array}$ & Percentage & $P$ & $\begin{array}{c}\text { Eradication } \\
\text { therapy }\end{array}$ \\
\hline \multicolumn{6}{|l|}{ Sex } \\
\hline Male & 136 & 91 & 67 & & 25 \\
\hline Female & 65 & 46 & 71 & 0.1 & 15 \\
\hline \multicolumn{6}{|l|}{ Age (years) } \\
\hline$<50$ & 21 & 15 & 71 & & 7 \\
\hline $50-70$ & 120 & 83 & 69 & & 25 \\
\hline$>70$ & 60 & 39 & 65 & 0.8 & 8 \\
\hline \multicolumn{6}{|c|}{ Primary disease treated surgically } \\
\hline Gastric cancer & 147 & 105 & 71 & & 34 \\
\hline Early & 100 & 72 & 72 & & 25 \\
\hline Advanced & 47 & 33 & 70 & & 9 \\
\hline Peptic ulcer & 45 & 26 & 58 & & 5 \\
\hline Others & 9 & 6 & 67 & 0.2 & 1 \\
\hline \multicolumn{6}{|c|}{ Interval after operation } \\
\hline$<2$ Years & 53 & 38 & 72 & & 17 \\
\hline 2-5 Years & 64 & 45 & 70 & & 13 \\
\hline$>5$ Years & 84 & 54 & 64 & 0.6 & 10 \\
\hline \multicolumn{6}{|c|}{ Reconstruction method } \\
\hline Billroth I & 126 & 91 & 72 & & 28 \\
\hline Billroth II & 51 & 30 & 59 & & 6 \\
\hline Others & 24 & 16 & 67 & 0.22 & 6 \\
\hline Total & 201 & 137 & 68 & & 40 \\
\hline
\end{tabular}

months) and histological examinations were performed. To compare H. pylori eradication rates, 330 nonsurgical patients with some upper abdominal complaint who had undergone $H$. pylori eradication therapy were also recruited (Table 2). As shown in Table 2, the unoperated $H$. pylori-treated patients were significantly younger $(P$ $<0.001)$ and peptic ulcer was more predominant $(P<$ $0.001)$ in comparison with the surgical patients treated for $H$. pylori. A total of 109 unoperated patients were followed endoscopically for more than 1 year after $H$. pylori eradication (average, 28 months), and histological examinations were performed.

This study was approved as ethical by the Nippon Medical School, Tokyo, Japan, and informed consent was obtained for $H$. pylori treatment and histological examinations.

\section{Gross endoscopic findings, histopathological} examination, and bacterological culture

Upper gastrointestinal endoscopy was performed after the patients fasted overnight. Routine endoscopic examination of the esophagus, remnant stomach, and anastomosis region was performed with a gastrointestinal fiberscope (GIF Type Q-240; Olympus, Tokyo, Japan). Macroscopic mucosal changes, i.e., erythema of the mucosa and edema of gastric folds and the presence of bile reflux and food residue were scored in four grades ( 0 , none; 1 , mild; 2 , moderate; and 3 , severe).
Mucosal biopsy specimens for the histological examination of the remnant stomach were collected with sterilized biopsy forceps (Olympus) from: (1) the greater curvature of the stoma, (2) the greater curvature of the upper corpus, and (3) the suture line of the lesser curvature. Biopsy specimens were also taken for culture from: (1) the stoma and (2) the upper corpus. In the unoperated stomach, biopsy specimens were taken from the antrum and the upper corpus for histological examination [13] and culture. The updated Sydney system was used for scoring inflammation (an increase in lymphocyte and plasma cells in the lamina propria); activity (density of neutrophil polymorphs in the lamina propria); and glandular atrophy, intestinal metaplasia, and $H$. pylori infection [14]. Hematoxylin-and-eosin staining, improved toluidine blue staining, and $H$. pylori specific-antibody (Ab) immunostaining (DAKO, Glostrup, Denmark) were used for the histological diagnosis of $H$. pylori infection in selected cases. Parameters of the updated Sydney system were scored in four grades ( 0 , none; 1 , mild; 2 , moderate; and 3 , severe). All biopsy specimens were examined by a pathologist (N.Y.) who was unaware of the results of the bacterial culture and the treatment regimens.

Biopsy specimens used for culture of $H$. pylori were immediately put into a transport tube with culture medium in a microaerophilic atmosphere (Seed tube HP; Eiken, Tokyo, Japan). On the same day, the biopsy specimens were transferred to the culture medium with 
Table 2. Characteristics of patients with $H$. pylori eradication therapy for the gastric remnant and the unoperated stomach

\begin{tabular}{|c|c|c|c|c|c|}
\hline & $\begin{array}{l}\text { Gastric } \\
\text { remnant }\end{array}$ & Percentage & $\begin{array}{c}\text { Unoperated } \\
\text { stomach }\end{array}$ & Percentage & $P$ \\
\hline \multicolumn{6}{|l|}{ Sex } \\
\hline Male & 25 & 63 & 224 & 68 & \\
\hline Female & 15 & 37 & 106 & 32 & 0.49 \\
\hline \multicolumn{6}{|l|}{ Age (years) } \\
\hline$<50$ & 7 & 17 & 118 & 36 & \\
\hline $50-70$ & 25 & 63 & 179 & 54 & \\
\hline$>70$ & 8 & 20 & 33 & 10 & $<0.001$ \\
\hline Smoker & 5 & 13 & 183 & 55 & $<0.001$ \\
\hline Alcohol drinker & 10 & 25 & 200 & 61 & $<0.001$ \\
\hline \multicolumn{6}{|l|}{ Disease } \\
\hline Gastric cancer & 34 & 85 & 13 & 4 & \\
\hline Peptic ulcer & 5 & 12 & 237 & 72 & \\
\hline Chronic gastritis & 0 & 0 & 65 & 20 & \\
\hline Others & 1 & 3 & 15 & 4 & $<0.001$ \\
\hline \multicolumn{6}{|l|}{ First-line therapy } \\
\hline Dual therapy & 20 & & 264 & & \\
\hline Eradication & 14 & 70 & 186 & 70 & 0.97 \\
\hline Triple therapy & 20 & & 66 & & \\
\hline Eradication & 18 & 90 & 58 & 88 & 0.89 \\
\hline Second-line therapy & 7 & & 73 & & \\
\hline Eradication & 7 & 100 & 65 & 89 & 0.79 \\
\hline Total & 40 & & 330 & & \\
\hline
\end{tabular}

Dual therapy, lansoprozole $30 \mathrm{mg}$ bid + amoxicillin (AMPC) $500 \mathrm{mg}$ tid + ecabet sodium $1.0 \mathrm{~g}$ bid $\times 14$ days; triple therapy, lansoprazole $30 \mathrm{mg}$ bid + AMPC $750 \mathrm{mg}$ bid + clarithromycin $(\mathrm{CAM})$ $400 \mathrm{mg}$ bid $\times 7$ days; second-line therapy: lansoprazole $30 \mathrm{mg}$ bid + AMPC $500 \mathrm{mg}$ tid + metronidazole $250 \mathrm{mg}$ tid + ecabet sodium $1.0 \mathrm{~g}$ bid $\times 14$ days

Skirrow plates and incubated at $35^{\circ} \mathrm{C}$ in an atmosphere of $5 \% \mathrm{O}_{2}, 10 \% \mathrm{CO}_{2}$, and $85 \% \mathrm{~N}_{2}$ for 3-7 days. Culture was judged to be positive for $H$. pylori based on colony morphology; the results of Gram staining; and positive oxidase, catalase, and urease activity. All of the bacterial cultures were performed at Mitsubishi Kagaku BCL (Tokyo, Japan).

\section{H. pylori eradication therapy}

Patients were deemed $H$. pylori-positive if the organism was identified either in culture or on histological examination, and $H$. pylori-negative if the organism was not detected by either method. Eradication was defined as the absence of $H$. pylori both in culture and on histological examination of biopsy specimens 4-6 weeks after the end of antimicrobial therapy.

Dual therapy was performed from June 1995 to October 2000, and triple therapy was performed from November 2000 to June 2002. In the study design for PPI-based dual therapy, patients with and without surgery received lansoprazole (Takeda Chemical Industries, Osaka, Japan) $30 \mathrm{mg}$ bid, amoxicillin (AMPC) $500 \mathrm{mg}$ tid, plus a mucosal protective agent (ecabet sodium; Tanabe Seiyaku, Osaka, Japan) $1.0 \mathrm{~g}$ bid for 2 weeks. For the PPI-based-triple therapy, patients with and without surgery received lansoprazole $30 \mathrm{mg}$ bid, AMPC $750 \mathrm{mg}$ bid, and clarithromycin (CAM) $400 \mathrm{mg}$ bid for 1 week. The second-line therapy for failure of both dual and triple therapy was lansoprazole $30 \mathrm{mg}$ bid, AMPC $500 \mathrm{mg}$ tid, metronidazole $250 \mathrm{mg}$ tid, plus ecabet sodium $1.0 \mathrm{~g}$ bid for 2 weeks.

Serum pepsinogen, gastrin, and $\mathrm{H}$. pylori antibody assay

Fasting blood samples were collected prior to eradication therapy, and the serum was stored at $-80^{\circ} \mathrm{C}$. Antibody to $H$. pylori was measured by enzyme-linked immunosorbent assay (E-plate; Eiken) in 164 of the 201 patients with distal gastrectomy, and a titer greater than $10 \mathrm{U} / \mathrm{ml}$ was considered positive. Pepsinogen I and II were measured with a radioimmunoassay RIA kit (Dainabot, Tokyo, Japan), and serum gastrin was measured with a radioimmunoassay kit (Dainabot). Serum assay was performed by Mitsubishi-Kagaku BCL (Tokyo, Japan).

\section{Statistical analysis}

Statistical analyses were performed by Student's $t$-test, Fisher's exact test, and the $\chi^{2}$ analysis program for PCs 
(SPSS, Tokyo, Japan). A $P$ value of less than 0.05 was considered significant.

\section{Results}

Characteristics of the patients with $\mathrm{H}$. pylori infection and eradication therapy in the gastric remnant

The overall $H$. pylori positive rate in the remnant stomach after distal gastrectomy was 137/201 (68\%), and the positive rate did not differ significantly according to sex, age, the primary disease treated surgically, interval after operation, or reconstruction method (Table 1). Forty $H$. pylori-positive patients with a remnant stomach were randomly enrolled for eradication therapy.

The serum pepsinogen I value and the pepsinogen I/ II ratio are established markers of glandular atrophy in the nonresected stomach [15], and the H. pylorinegative group had a significantly higher pepsinogen $\mathrm{I} / \mathrm{II}$ ratio $(3.16 \pm 3.32$; mean $\pm \mathrm{SD})$ than the positive group $(1.86 \pm 0.73 ; P<0.001)$ and a significantly lower serum $H$. pylori-antibody titer $(182 \pm 236 \mathrm{U} / \mathrm{ml})$ than the positive group $(306 \pm 243 \mathrm{U} / \mathrm{ml} ; P<0.01)$ in the remnant stomach. Among those in whom both histological examination and bacterial culture were negative for $H$. pylori in the remnant stomach, only $10 / 48(21 \%)$ had negative serum anti- $H$. pylori antibody titers. Serum pepsinogen I and gastrin levels were not significantly different in the remnant stomachs that were $H$. pylori-positive $(25.5 \pm 17.0 \mathrm{ng} / \mathrm{ml}$ and $41.2 \pm 23 \mathrm{pg} / \mathrm{ml}$, respectively) and those that were negative (36.4 \pm $78.9 \mathrm{ng} / \mathrm{ml}$ and $38.7 \pm 28 \mathrm{pg} / \mathrm{ml}$, respectively).

\section{H. pylori eradication rate in the remnant stomach and} the unoperated stomach

Forty $H$. pylori-positive patients after distal gastrectomy were treated with PPI-based dual or triple therapy. A double dose of lansoprazole (60 mg per day) and AMPC $1500 \mathrm{mg}$ per day was used for PPI-based dual therapy. A regular dose (2.0 g per day) of the mucosal protective agent; ecabet sodium, was added to prevent adverse effects and because of its slight inhibitory effect on $H$. pylori growth [16]. Dual therapy was continued for 2 weeks, and the eradication rate in the remnant stomach was 14/20 (70\%), using per-protocol analysis. For comparison, the eradication rate of dual therapy with the same regimen in the 264 of 330 patients with an unoperated stomach who received this therapy was $70 \%$ (186/264). The characteristics of the patients with unoperated stomachs are shown in Table 2. They were significantly younger, included more smokers and alcohol drinkers, and were peptic ulcer patients $(P<$ $0.001)$ predominantly compared with the remnant stom- ach group. The protocol of the PPI-based triple therapy was a double dose of lansoprazole (60 mg per day), AMPC $1500 \mathrm{mg}$ per day, and clarithromycin $800 \mathrm{mg}$ per day for 1 week. The eradication rate for the triple therapy in the remnant stomach was $90 \%$ (18/20), using per-protocol analysis, and this was comparable to the rate of $88 \%(58 / 66)$ in the unoperated stomach.

Patients in whom both dual and triple therapy failed, except for 14 dropout patients, were immediately enrolled into a second-line therapy group without testing for antibiotic sensitivity. The protocol of the secondline therapy consisted of a double dose of lansoprazole $(60 \mathrm{mg}$ ) per day, AMPC $1500 \mathrm{mg}$ per day, metronidazole $750 \mathrm{mg}$ per day, and ecabet sodium $2.0 \mathrm{~g}$ per day for 2 weeks. The eradication rate for second-line therapy, using per-protocol analysis, was $7 / 7(100 \%)$ in the remnant stomach and 65/73 (89\%) in the unoperated stomach. There was no significant difference in the eradication rate by second-line therapy between the unoperated patients who had had dual therapy and those who had had triple therapy $(57 / 65$ vs $8 / 8$, respectively; $P=0.65$ ).

The main side effect of eradication therapy was diarrhea (Table 3). Diarrhea occurred in $4 / 40(10 \%)$ of the remnant-stomach patients and in 19/330 (5.8\%) of the unoperated patients, and it diminished after therapy without any additional medication. No other side effects occurred in the remnant-stomach group, but other side effects occurred in 25 of the 330 (7.6\%) unoperated patients. Gastroesophageal reflux disease (GERD) developed after eradication therapy in $2 / 40(5 \%)$ of the remnant stomach patients and in $9 / 330(2.7 \%)$ of the unoperated patients. The overall incidence of side effects was $6 / 40(15 \%)$ in the remnant-stomach group and $53 / 330(16 \%)$ in the unoperated group, and the difference was not significant $(P=0.96)$. Patients with a past history of penicillin allergy were excluded from firstand second-line therapy. Unexpectedly, 2/40 (5\%) of the operated patients experienced an improvement in bowel movements after $H$. pylori eradication therapy (Table 3).

\section{Sequential histopathological changes in the remnant stomachs with and without eradication therapy}

Histopathological mucosal changes in the remnant stomachs after successful eradication therapy were scored according to the updated Sydney system. As shown in Fig. 1, the inflammation score was significantly decreased 4-6 weeks after the end of treatment $(P<$ 0.001 ), when eradication was diagnosed, and it decreased even more after 1 year (average, 19 months; $P$ $<0.001)$. The activity score was significantly decreased 4-6 weeks after the end of treatment $(P<0.001)$, and no significant difference was found after 1 year or more. 
Table 3. Incidence of side effects of PPI-based dual and triple therapies in patients with a remnant stomach and those with an unoperated stomach

\begin{tabular}{|c|c|c|c|c|c|c|c|c|}
\hline \multirow[b]{2}{*}{ Side effects } & \multicolumn{4}{|c|}{ Remnant stomach $(n=40)$} & \multicolumn{4}{|c|}{ Unoperated stomach $(n=330)$} \\
\hline & $\begin{array}{c}\text { Dual } \\
\text { therapy }\end{array}$ & $\begin{array}{l}\text { Triple } \\
\text { therapy }\end{array}$ & Total & Percentage & $\begin{array}{c}\text { Dual } \\
\text { therapy }\end{array}$ & $\begin{array}{l}\text { Triple } \\
\text { therapy }\end{array}$ & Total & Percentage \\
\hline \multicolumn{9}{|l|}{ Adverse event } \\
\hline None & 17 & 17 & 34 & 85 & 223 & 54 & 277 & 84 \\
\hline Diarrhea & 2 & 2 & 4 & 10 & 13 & 6 & 19 & 6 \\
\hline Taste disturbance & 0 & 0 & 0 & 0 & 4 & 3 & 7 & 2 \\
\hline Nausea & 0 & 0 & 0 & 0 & 7 & 0 & 7 & 2 \\
\hline Skin rash & 0 & 0 & 0 & 0 & 11 & 0 & 11 & 3 \\
\hline GERD after treatment & 1 & 1 & 2 & 5 & 6 & 3 & 9 & 3 \\
\hline \multicolumn{9}{|l|}{ Symptom amelioration } \\
\hline None & 18 & 18 & 36 & 90 & & & & \\
\hline Bowel movement & 2 & 2 & 4 & 10 & & & & \\
\hline
\end{tabular}

GERD, gastroesophageal reflux disease; PPI, proton pump inhibitor

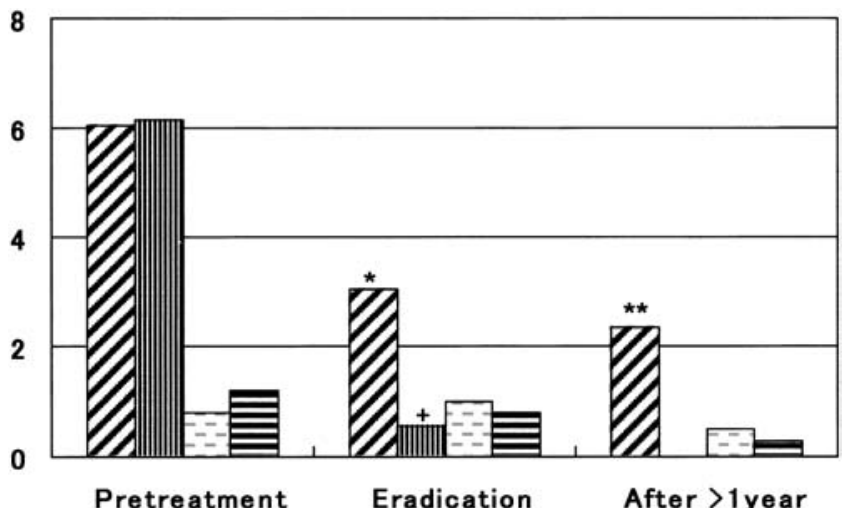

Fig. 1. Sequential histological changes in the mucosa in the remnant stomach after successful Helicobacter pylori eradication therapy, scored according to the updated Sydney system [14]. The scores for each parameter at three points: (1) stoma, (2) greater curvature of the upper corpus, and (3) the suture line of the lesser curvature, were added. The inflammation score (diagonally striped bars) was significantly decreased when eradication was diagnosed (4-6 weeks after the end of treatment; $* P<0.001$, and it decreased even more after more than 1 year $(* * P<0.001)$. The activity score (vertically striped bars) was significantly decreased after eradication $\left({ }^{+} P<0.001\right)$ and fell to almost zero after more than 1 year. The atrophy score (dashed-line bars) and intestinal metaplasia score (horizontally striped bars) did not significantly change after treatment

These scores did not differ according to the three biopsy sites, i.e., stoma, upper corpus, and suture line. There was no change in glandular atrophy and intestinal metaplasia scores after treatment.

In the remnant stomachs without $H$. pylori treatment, the inflammation and activity scores were significantly higher in $H$. pylori-positive mucosa than in the negative mucosa $(P<0.001)$, and the follow-up study showed a significant increase in inflammation and activity scores

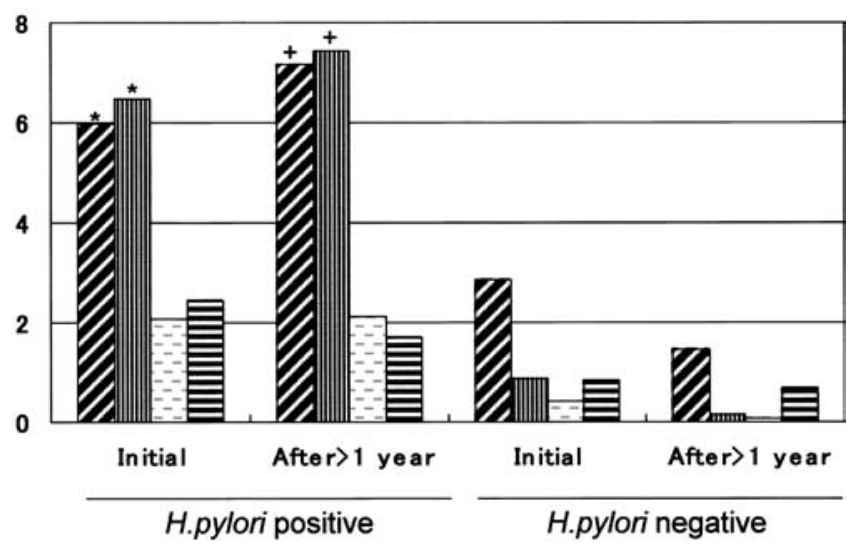

Fig. 2. The inflammation and activity scores in the remnant stomachs without $H$. pylori treatment were significantly higher in $H$. pylori-positive mucosa than in-negative mucosa $\left({ }^{*} P<0.001\right)$, and there were significant increases in the inflammation and activity scores $\left({ }^{+} P<0.001\right)$ in the $H$. pyloripositive mucosa after an average of 32 months. The scores for each parameter at three points (1,2, and 3 as in Fig. 1 legend) were added. Bars, as in Fig. 1

$(P<0.001)$ in the H. pylori-positive mucosa after an average of 32 months (Fig. 2). No changes in these scores were detected in the H. pylori-negative mucosa during the same period.

Sequential changes in endoscopic gross findings in the remnant stomach after eradication therapy

The endoscopic gross findings changed after eradication (mean, 15 months after treatment). The scores for erythema of the mucosa (pre, 1.20 vs post, 1.25 ) and bile reflux (1.12 vs 1.25) in the remnant stomach were increased $(P<0.05)$, but the score for edema of the folds decreased after eradication $(1.29$ vs $1.20 ; P<0.01)$. 
Food residue was observed in a few patients $(5 / 40 ; 13 \%)$ in this study, but the scores did not significantly change after eradication therapy (before, 0.29 vs after, 0.1).

\section{Discussion}

Recent prospective studies in humans and experiments in Mongolian gerbils have shown a close association between $H$. pylori infection in the stomach and gastric cancer [6,17-19], similar to findings in earlier epidemiological studies [4]. The mucosa of the remnant stomach after surgery for early gastric cancer is at high risk for metachronous multiple gastric cancer. An endoscopic finding of erythema in the remnant stomach is correlated with bile reflux, and histological chronic active gastritis is correlated with $H$. pylori infection $[3,20]$. Many data have indicated that bile (alkaline) reflux is a causative factor in stump cancer after distal gastrectomy for peptic ulcer [1,2]. However, H. pylori infection in the remnant stomach may be a causative factor in remnant gastric cancer after gastrectomy for gastric cancer [11].

H. pylori eradication therapy is strongly recommended after surgery for early gastric cancer [8], based on supportive evidence that it prevents the development of new cancers after endoscopic mucosal resection (EMR) for intramucosal gastric cancer $[9,10]$. Some reports emphasize the importance of $H$. pylori treatment at a young age $[21,22]$. However, these studies conclude that $H$. pylori eradication is also useful for the prevention of new cancer development from high-risk mucosa of gastric cancer [23].

The regimen for $H$. pylori eradication therapy has been established, and PPI-based triple therapy is the standard throughout the world [8,24]. The protocol for H. pylori eradication in the remnant stomach, however, has not been established, and the extent to which the efficacy of PPI-based dual and triple therapies is related to the topical action of the antimicrobials and how much is attributable to their systemic action is unclear, but both are probably important. Thus, there has been concern that the topical action of the antimicrobials is ineffective in the remnant stomach because of the possible rapid transit of the drugs from the small remnant stomach into the duodenum or small intestine. However, the results of the present study clearly showed the same eradication rates for both PPI-based dual therapy and triple therapy in the unoperated stomach and remnant stomach after surgery.

We used lansoprazole as the PPI because it possesses some antibacterial activity against $H$. pylori [25], and lansoprazole-based triple therapy was approved for treatment for $H$. pylori by the National Health Insurance in Japan on November 1, 2000. A mucosal protec- tive agent, ecabet sodium, obtained from a derivative of pine resin in Japan, was used for dual therapy, and several mucosal protective effects have been reported [15]. Ecabet sodium attaches to the gastric mucosa and inhibits $H$. pylori urease activity in vitro, and the addition of ecabet sodium has been reported to enhance the eradication rate of dual therapy [26].

Second-line therapy for treatment-failure patients is a great problem, and standard second regimens have been under investigation around the world. We used two antibiotics, AMPC and metronidazole [27]. H. pylori resistant to CAM have been found in more than half of the patients in whom first-line triple therapy failed, but hardly any colonies were AMPC-resistant. Metronidazole-resistant $H$. pylori is relatively uncommon in Japan [28], and several reports have indicated substantial eradication of $H$. pylori with metronidazole in patients with metronidazole-resistant colonies [29]. Murakami et al. [29] studied eradication rates with a PPI + AMPC + metronidazole second-line regimen, given for 1 week, according to the metronidazole sensitivity of $H$. pylori, and the results showed a $96.8 \%$ eradication rate in patients with metronidazole-sensitive $H$. pylori vs $81.8 \%$ in patients with metronidazole-resistant H. pylori. We did not check antibiotic sensitivity before second-line therapy, but we obtained similar satisfactory eradication rates in both the unoperated and the remnant stomachs.

The major side effect of the dual and triple therapies was diarrhea, which occurred in about $6 \%-10 \%$ of patients, and there was no significant difference between the incidence in patients with unoperated and those with remnant stomachs. Gastroesophageal reflux disease (GERD) after $H$. pylori therapy has attracted attention [30]. Exacerbation of GERD was found in 5\% of remnant-stomach patients after $H$. pylori eradication, although no long-term effect was clear from this study. Some postoperative complaints, such as a feeling of fullness, were unchanged after the eradication therapy, but a few patients $(10 \%)$ in the remnant-stomach group experienced improvement in bowel movements after treatment.

H. pylori-positivity in the remnant stomach did not differ according to any of the clinical characteristics in this study. A previous study showed that age, reconstruction (anastomosis) method [31], and postoperative follow-up period [20] affected H. pylori-positivity, because bile reflux interferes with $H$. pylori survival [32]. Serum was positive for anti-H. pylori-antibody in $80 \%$ of the $H$. pylori-negative patients based on both the histological examinations and bacterial culture. We previously reported that, even after total gastrectomy, more than 1 year was necessary for negative seroconversion to anti-H. pylori antibody [33]. Thus, the H. pylori colonizing the middle to lower stomach before 
the operation were removed by distal gastrectomy, but in many patients serum antibody against $H$. pylori persisted for more than 1 year after the operation. Serum pepsinogen I and II assays are not only useful for detecting chronic atrophic gastritis without X-ray or endoscopic examinations but they have also been useful in mass screening Japanese for gastric cancer [15]. A low pepsinogen I/II ratio $(<3.0)$ is an especially good marker for indicating a high risk of gastric cancer [15], and $H$. pylori infection has been correlated with a lower pepsinogen I/II ratio [34]. After distal gastrectomy in the present study as well, the $H$. pylori-positive remnant stomachs also had a significantly lower pepsinogen I/II ratio than the $H$. pylori-negative remnant stomachs.

Lymphocyte and leukocyte infiltration of the lamina propria was detected to almost the same extent in the stoma, upper corpus, and suture line of the H. pyloripositive remnant stomachs. In the $H$. pylori-positive remnant stomachs, infiltration by these inflammatory cells increased after an average of 32 months of followup, whereas minimal inflammatory cell infiltration was found in the $H$. pylori-negative remnant stomachs. After eradication, the inflammatory cell infiltration quickly decreased during the 4-6 weeks after treatment, when chronic inactive gastritis was observed, as scored by the updated Sydney system [14]. Chronic inactive gastritis persisted for more than 1 year, but the scores for glandular atrophy and intestinal metaplasia, possible precursory lesions of gastric cancer [7], were unchanged. The changes in scores after the eradication therapy were exactly the same as the changes in scores for the upper corpus of the unoperated stomach (data not shown).

The endoscopic findings in the remnant stomach were also influenced by $H$. pylori eradication therapy. Gross features of erythema were observed in the remnant stomach. Our data showed a positive correlation $(r=$ 0.92; $P<0.001$ ) between the grade of erythema in the remnant stomach and the degree of 24-h bile reflux, determined with Bilitec 2000 (Synectics Medical, Stockholm, Sweden; data not shown). Erythema and bile reflux were slightly increased 15 months after the eradication therapy, but edema of the folds had decreased significantly. Inflammatory cell infiltration of the lamina propria in $H$. pylori infection causes edema of gastric tissue, and, thus, it is not surprising that the endoscopic gross findings showed a decrease in edema after eradication.

In conclusion, (1) the same regimens of $H$. pylori eradication therapy were as applicable to the remnant stomach after distal gastrectomy as to the unoperated stomach, (2) clinical symptoms in operated patients were not changed significantly after the eradication therapy, and (3) chronic active gastritis immediately converted to inactive gastritis after the eradication therapy, but the glandular atrophy and intestinal metaplasia in the remnant stomach were unchanged after a middle-term observation period.

Acknowledgments This work was supported in part by a Grant-in-Aid for Cancer Research (9-3) from the Ministry of Health, Labor, and Welfare of Japan, and by a Grant-in-Aid for Scientific Research (C) from the Ministry of Education, Science, Sports, and Culture of Japan.

\section{References}

1. Toftgaard C. Gastric cancer after peptic ulcer surgery: a historic prospective cohort investigation. Ann Surg 1989;210:159-64.

2. Fiore AC, Malangoni MA, Broadie TA, Madura JA, Jesseph JE. Surgical management of alkaline reflux gastritis. Arch Surg 1982;117:689-94.

3. Matsukura N, Onda M. Gastric remnant-stump cancer and Helicobacter pylori (in Japanese). Gastroenterol Surg 2000;23: 1133-8.

4. IARC Working Group on the Evaluation of Carcinogenic Risks to Humans. Schistosomes, liver flukes and Helicobacter pylori. IARC Monographs on the Evaluation of Carcinogenic Risks to Humans 61. Lyon: IARC; 1994. p. 177-241.

5. Uemura N, Okamoto S, Yamamoto S, Matsumura N, Yamaguchi $\mathrm{S}$, Yamakido M, et al. Helicobacter pylori infection and the development of gastric cancer. N Engl J Med 2001;345:784-9.

6. Sugiyama A, Maruta F, Ikeno T, Ishida K, Kawasaki S, Katsuyama T, et al. Helicobacter pylori infection enhances Nmethyl-N-nitrosourea-induced stomach carcinogenesis in the Mongolian gerbils. Cancer Res 1998;58:2067-9.

7. Correa P. Human gastric carcinogenesis: a multistep and multifactorial process. First American Cancer Society Award Lecture On Cancer Epidemiology and Prevention. Cancer Res 1992;52:673540.

8. The European Helicobacter pylori study group. Current European concepts in the management of Helicobacter pylori infection. The Maastricht Consensus Report. Gut 1997;41:813 .

9. Uemura N, Mukai T, Okamoto S, Yamaguchi S, Mashiba H, Taniyama K, et al. Effect of Helicobacter pylori eradication on subsequent development of cancer after endoscopic resection of early gastric cancer. Cancer Epidemiol Biomarkers Prev 1997;6: 639-42.

10. Saito K, Arai K, Mori M, Kobayashi R, Ohki I. Effect of Helicobacter pylori eradication on malignant transformation of gastric adenoma. Gastrointest Endosc 2000;52:27-32.

11. Nagahata Y, Kawakita N, Azumi Y, Numata N, Yano M, Saitoh Y. Etiological involvement of Helicobacter pylori in "reflux" gastritis after gastrectomy. Am J Gastroenterol 1996;91:2130-4.

12. Rino Y, Imada T, Shiozawa M, Takahashi M, Fukuzawa K, Hasuo $\mathrm{K}$, et al. Helicobacter pylori of the remnant stomach and its eradication. Hepatogastroenterology 1999;46:2069-73.

13. Yamada N, Matsukura N, Matsuhisa T. Triple site biopsy under endoscopy (in Japanese with English abstract). Nippon Rinsho (Jpn J Clin Med) 2001;59:252-7.

14. Dixon MF, Genta RM, Yardely JH, Correa P. Classification and grading of gastritis. The updated Sydney system. Am J Surg Pathol 1996;20:1161-81.

15. Miki K, Ichinose M, Kawamura N, Matsushima M, Ahmad HB, Kimura M, et al. The significance of low serum pepsinogen levels to detect stomach cancer associated with extensive chronic gastritis in Japanese subjects. Jpn J Cancer Res 1989;80:111-4. 
16. Shibata K, Ito Y, Hongo A, Yasoshima A, Endo T, Ohashi M. Bactericidal activity of a new antiulcer agent, ecabet sodium, against Helicobacter pylori under acidic conditions. Antimicrob Agents Chemother 1995;39:1295-9.

17. Watanabe T, Tada M, Nagai H, Sasaki S, Nakao M. Helicobacter pylori infection induces gastric cancer in Mongolian gerbils. Gastroenterology 1998;115:642-8.

18. Honda S, Fujioka T, Tokieda M, Satoh R, Nishizono A, Nasu M. Development of Helicobacter pylori-induced gastric carcinoma in Mongolian gerbils. Cancer Res 1998;58:4255-9.

19. Hirayama F, Takagi S, Iwao E, Yokoyama Y, Haga K, Hanada S. Development of poorly differentiated adenocarcinoma and carcinoid due to long-term Helicobacter pylori colonization in Mongolian gerbils. J Gastroenterol 1999;34:450-4.

20. Onoda N, Maeda K, Sawada T, Wakasa K, Arakawa T, Chung $\mathrm{KH}$. Prevalence of Helicobacter pylori infection in gastric remnant after distal gastrectomy for primary gastric cancer. Gastric Cancer 2001;4:87-92.

21. Kikuchi S. Epidemiology of Helicobacter pylori and gastric cancer. Gastric Cancer 2002;5:6-15.

22. Blaser MJ, Chyou PH, Nomura A. Age at establishment of Helicobacter pylori infection and gastric carcinoma, gastric ulcer and duodenal ulcer risk. Cancer Res 1995;55:562-5.

23. Shimizu N, Ikehara Y, Inada K, Nakanishi H, Tsukamoto T, Nozaki K, et al. Eradication diminishes enhancing effects of Helicobacter pylori infection on glandular stomach carcinogenesis in Mongolian gerbils. Cancer Res 2000;60:1512-4.

24. Miwa H, Nagahata A, Sato K, Ohkura R, Murai T, Shimizu H, et al. Efficacy of 1 week omeprazole or lansoprazole-amoxicillinclarithromycin therapy for Helicobacter pylori infection in the Japanese population. J Gastroenterol Hepatol 1999;14:317-21.

25. Nagata K, Satoh H, Iwahi T, Shimoyama T, Tamura T. Potent inhibitory action of the gastric proton pump inhibitor lansoprazole against urease activity of Helicobacter pylori: unique action selective for $H$. pylori cells. Antimicrob Agents Chemother 1993;37:769-74.

26. Kagaya H, Kato M, Komatsu Y, et al. High-dose ecabet sodium improves the eradication rate of Helicobacter pylori in dual therapy with lansoprazole and amoxicillin. Aliment Pharmacol Ther 2000;14:1523-7.

27. Takimoto T, Satoh K, Taniguchi Y, Saifuku K, Kihira K, Seki M, et al. The efficacy and safety of 1-week triple therapy with lansoprazole, clarithromycin, and metronidazole for the treatment of Helicobacter pylori infection in Japanese patients. Helicobacter 1997;2:86-91.

28. Kato M, Yamaoka Y, Kim JJ, Reddy R, Asaka M, Kashima K, et al. Regional differences in metronidazole resistance and increasing clarithromycin resistance among Helicobacter pylori isolates from Japan. Antimicrob Agents Chemother 2000;44: 2214-6.

29. Murakami K, Sato R, Okimoto T, Nasu M, Fujioka T, Kodama M, et al. Efficacy of triple therapy comprising rabeprazole, amoxicillin and metronidazole for second-line Helicobacter pylori eradication in Japan, and the influence of metronidazole resistance. Aliment Pharmacol Ther 2003;17:119-23.

30. Labenz J, Blum AL, Bayerdörffer E, Meining A, Stolte M, Borsch G. Curing Helicobacter pylori infection in patients with duodenal ulcer may provoke reflux esophagitis. Gastroenterology 1997; 112:1442-7.

31. Tomtitchong P, Onda M, Matsukura N, Tokunaga A, Kato S, Matsuhisa T, et al. Helicobacter pylori infection in the remnant stomach after gastrectomy: with special reference to the difference between Billroth I and II anastomosis. J Clin Gastroenterol 1998;27:S154-8.

32. Han SW, Evans DG, el-Zaatari FA, Go MF, Graham DY. The interaction of $\mathrm{pH}$, bile and Helicobacter pylori may explain duodenal ulcer. Am J Gastroenterol 1996;91:1135-7.

33. Matsukura N, Onda M, Tokunaga A, Kato S, Kyono S, Yamashita K. Tissue IgA antibody against Helicobacter pylori in patients with gastroduodenal disease: comparison with bacterial culture, serum $\operatorname{IgG}$ antibody, and $\left[{ }^{13} \mathrm{C}\right]$ urea breath test. J Clin Gastroenterol 1995;21:S146-50.

34. Asaka M, Kimura T, Kudo M, Takeda H, Mitani S, Miyazaki T, et al. Relationship of Helicobacter pylori to serum pepsinogens in an asymptomatic Japanese population. Gastroenterology 1992;102: $760-6$. 